\title{
Analisis Produktivitas Maksimum Penggunaan Lahan Pasar Pucang Anom Surabaya dengan Metode HBU (Highest and Best Use)
}

\author{
Dian Pararta Laksmi dan Christiono Utomo \\ Departemen Teknik Sipil, Fakultas Teknik Sipil dan Perencanaan, Institut Teknologi Sepuluh Nopember (ITS) \\ e-mail: christiono@ce.its.ac.id; dianpararta@gmail.com
}

\begin{abstract}
Abstrak-Pasar tradisional merupakan salah satu tempat terjadinya aktivitas pusat perdagangan. Namun, seiring dengan berkembangnya zaman keberadaan pasar tradisional semakin ditinggalkan. Salah satunya adalah keberadaan Pasar Pucang Anom yang terletak di Jalan Pucang Anom, Surabaya. Kondisi pasar di lantai kedua sepi dan kurang peminat. Selain itu, kondisi pasar sudah tua dan terlihat kumuh. Oleh karena itu perlu dilakukan penghidupan kembali pada Pasar Pucang Anom agar pasar dapat menghasilkan nilai lahan tertinggi. Alternatif penggunaan lahan pada Pasar Pucang Anom Surabaya ini dianalisis menggunakan metode Highest and Best Use. Analisa ini meliputi aspek legal, aspek fisik, aspek finansial dan produktivitas maksimum. Hasil penelitian ini didapatkan alternatif mixed used antara pasar dan apartemen sebagai alternatif penggunaan lahan terbaik dengan nilai lahan

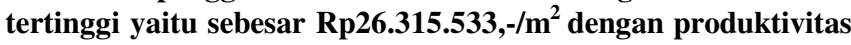
maksimum sebesar $210 \%$.
\end{abstract}

Kata Kunci-HBU, Lahan, Pasar, Produktivitas Maksimum.

\section{PENDAHULUAN}

K OTA Surabaya sebagai ibu kota provinsi Jawa Timur dan salah satu kota metropolitan terbesar di Indonesia memiliki pertumbuhan aktivitas kota yang pesat. Salah satu aspek yang menunjang pertumbuhan kota adalah aspek perdagangan, misalnya keberadaan pasar tradisional. Terdapat banyak pasar tradisional yang lokasinya tidak sesuai dengan rencana awal pembangunan karena adanya perkembangan kota. Hal tersebut mengakibatkan fungsi pasar tradisional yang tidak optimal. Salah satu contohnya adalah Pasar Pucang Anom.

Pasar Pucang Anom yang terletak di Jalan Pucang Anom, Surabaya dengan luas area sebesar $11.615 \mathrm{~m}^{2}$ dengan luas bangunan sebesar $12.000 \mathrm{~m}^{2}$. Kondisi pasar yang sudah tua, kotor, kumuh, dan kapasitas parkir yang kurang memadai mengakibatkan kondisi pasar terasa tidak nyaman. Kondisi stan di lantai pertama yang terdiri dari buah-buahan, sayursayuran, daging dan kios sembako terlihat sangat padat. Keadaan tersebut berbeda dengan kondisi stan di lantai ke dua yang yang sepi pengunjung. Hal itu dipengaruhi oleh lokasi pasar yang dikelilingi oleh properti komersial yang mengakibatkan turunnya minat masyarakat untuk berkunjung ke pasar. Oleh karena itu perlu dilakukan revitalisasi pada Pasar Pucang Anom menggunakan analisis penggunaan lahan tertinggi dan terbaik sebagai tahap awal untuk memahami revitalisasi pada Pasar Pucang Anom tanpa menghilangkan keberadaan pasar tradisional sebagai fungsi utama.

Metode yang akan digunakan untuk mengetahui nilai tertinggi dan terbaik dari lahan pasar tersebut adalah analisa Highest and Best Use (HBU). Definisi Highest and Best Use adalah penggunaan yang paling memungkinkan dan diizinkan dari suatu tanah yang kosong atau tanah yang sudah dibangun, yang mana secara fisik memungkinkan, didukung atau dibenarkan oleh peraturan, layak secara keuangan dan menghasilkan nilai tertinggi [1]. Lokasi Pasar Pucang Anom dapat di lihat pada Gambar 1.

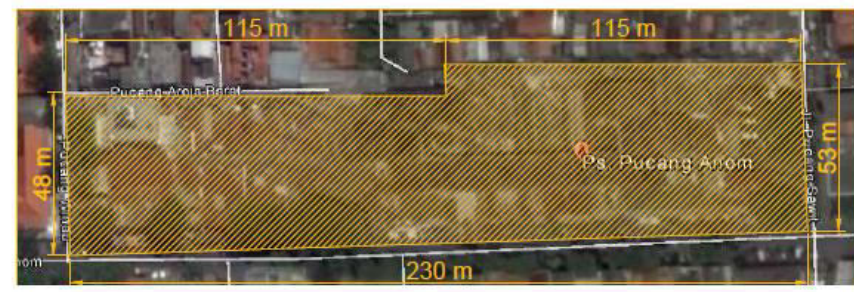

Gambar 1. Lokasi Lahan Pasar Pucang Anom yang terletak di Jalan Pucang Anom, Surabaya dengan lahan seluas $11.615 \mathrm{~m}^{2}$.

\section{PENELITIAN TERDAHULU}

Sudah cukup banyak penelitian yang membahas HBU, diantaranya adalah penelitian [2], [3], [4], [5], [6], [7], [8] dan [9]. Penelitian [2] menganalisis lahan Pasar Turi Lama yang sudah tidak difungsikan lagi, penelitian [3] menganalisis lahan Pasar Blauran Surabaya, penelitian [4] menganalisis lahan Pasar Genteng Baru Surabaya dan penelitian [5] menganalisis lahan Pasar Gubeng Masjid Surabaya. Penelitian [2], [3], [4], dan [5] memiliki persamaan yaitu menganalisis lahan pasar tradisional dan tetap mempertimbangkan keberadaan pasar tradisional sebagai alternatif penggunaan lahan.

Perbedaannya antara lain penelitian [2] dan [5] melakukan pengamatan terhadap lokasi objek, penyebaran kuesioner dan wawancara kepada stakeholder untuk menentukan pemilihan alternatif awal, sedangkan penelitian [3] dan [4] melakukan pengamatan terhadap lokasi objek dan penyebaran kuesioner untuk menentukan pemilihan alternatif awal.

Berdasarkan keseluruhan penelitian tersebut terdapat beberapa persamaan mendasar dengan penelitian terdahulu yaitu penelitian ini bertujuan untuk mendapatkan keputusan investasi properti terbaik dan persamaan dalam hal metode analisa yang digunakan yaitu menggunakan analisa pada aspek legal, fisik, finansial dan produktivitas maksimum. Persamaan lainnya adalah dalam kelayakan investasi digunakan kriteria NPV (Net Present Value) untuk mengukur tingkat penerimaan investasi. 


\section{METODOLOGI}

Penelitian ini menggunakan analisa penggunaan tertinggi dan terbaik untuk menganalisis objek lahan yang ditinjau. Analisa ini terdiri dari variabel penelitian yang dapat dilihat pada Tabel 1 .

Tabel 1.

Variabel dan Klasifikasi Analisa Data

\begin{tabular}{|c|c|c|c|c|}
\hline No. & Variabel & Klasifikasi & Jenis Data & Sumber Data \\
\hline 1. & $\begin{array}{l}\text { Penentuan } \\
\text { Alternatif }\end{array}$ & $\begin{array}{l}\text { Alternatif } \\
\text { penggunaan lahan } \\
\text { Pasar Pucang } \\
\text { Anom Surabaya }\end{array}$ & $\begin{array}{l}\text { Data } \\
\text { primer }\end{array}$ & $\begin{array}{l}\text { Pengamatan } \\
\text { perkembangan } \\
\text { bangunan di } \\
\text { sekitar objek } \\
\text { penelitian }\end{array}$ \\
\hline 2. & Aspek Legal & $\begin{array}{ll}\text { a. } & \text { Zonasi } \\
\text { b. } & \text { Building Code }\end{array}$ & $\begin{array}{l}\text { Data } \\
\text { sekunder }\end{array}$ & $\begin{array}{l}\text { Dinas Cipta } \\
\text { Karya dan Tata } \\
\text { Ruang Kota } \\
\text { Surabaya }\end{array}$ \\
\hline 3. & Aspek Fisik & $\begin{array}{l}\text { a. Lokasi lahan } \\
\text { b. Bentuk } \\
\text { dan ukuran } \\
\text { lahan } \\
\text { c. Aksesibilitas } \\
\text { d. Utilitas }\end{array}$ & $\begin{array}{l}\text { Data } \\
\text { primer } \\
\text { dan } \\
\text { sekunder }\end{array}$ & $\begin{array}{l}\text { Pengamatan } \\
\text { lahan dan lokasi } \\
\text { di sekitar lahan }\end{array}$ \\
\hline 4. & $\begin{array}{l}\text { Aspek } \\
\text { Finansial }\end{array}$ & $\begin{array}{l}\text { a. Biaya investasi } \\
\text { b. Pendapatan } \\
\text { c. Pengeluaran } \\
\text { d. Aliran kas }\end{array}$ & $\begin{array}{l}\text { Data } \\
\text { sekunder }\end{array}$ & $\begin{array}{l}\text { a. PT PLN } \\
\text { b. PDAM } \\
\text { c. Market } \\
\text { research }\end{array}$ \\
\hline 5. & $\begin{array}{l}\text { Produktivita } \\
\text { s Maksimum }\end{array}$ & Nilai lahan & $\begin{array}{l}\text { Data } \\
\text { sekunder }\end{array}$ & $\begin{array}{l}\text { Berdasarkan } \\
\text { perhitungan } \\
\text { aspek finansial } \\
\end{array}$ \\
\hline
\end{tabular}

\section{DISKUSI DAN PEMBAHASAN}

\section{A. Penentuan Alternatif}

Berdasarkan hasil pengamatan dan penyebaran kuesioner/wawancara didapatkan alternatif yang memungkinkan untuk dibangun pada lahan Pasar Pucang Anom adalah revitalisasi pasar, hotel, apartemen, pujasera, dan pertokoan. Dari pilihan alternatif tersebut, ditentukan 4 alternatif yaitu sebagai berikut:

a. Alternatif 1

- Pasar tradisional

- Pertokoan

- Pujasera

- Apartemen

- Hotel

b. Alternatif 2

- Pasar tradisional

- Pertokoan

- Pujasera

c. Alternatif 3

- Pasar tradisional

- Apartemen

d. Alternatif 4

- Pasar tradisional

- Hotel

\section{B. Aspek Legal}

Berikut adalah data yang didapatkan dari Dinas Cipta Karya dan Tata Ruang Kota Surabaya mengenai building code dan keperuntukkan lahan pada Pasar Pucang Anom [8]:

1. Keperuntukan Lahan sebagai Perdagangan dan Jasa Komersial
2. Garis Sempadan Bangunan (GSB) untuk sisi depan $4 \mathrm{~m}$, tampak belakang $3 \mathrm{~m}$, dan tampak kiri $3 \mathrm{~m}$.

3. Koefisien Dasar Bangunan (KDB) maksimum $60 \%$

4. Koefisien Lantai Bangunan (KLB) maksimum 500\%

5. Koefisien Daerah Hijau (KDH) minimum 10\%

6. Jumlah lantai maksimal adalah 5 lantai.

Berdasarkan analisis aspek legal, didapatkan luas dasar bangunan maksimal adalah $6.969 \mathrm{~m}^{2}$, luas lantai bangunan maksimal adalah $34.845 \mathrm{~m}^{2}$ dan jumlah lantai maksimal adalah 5 lantai. Diagram Alir penelitian dapat di lihat pada Gambar 2.

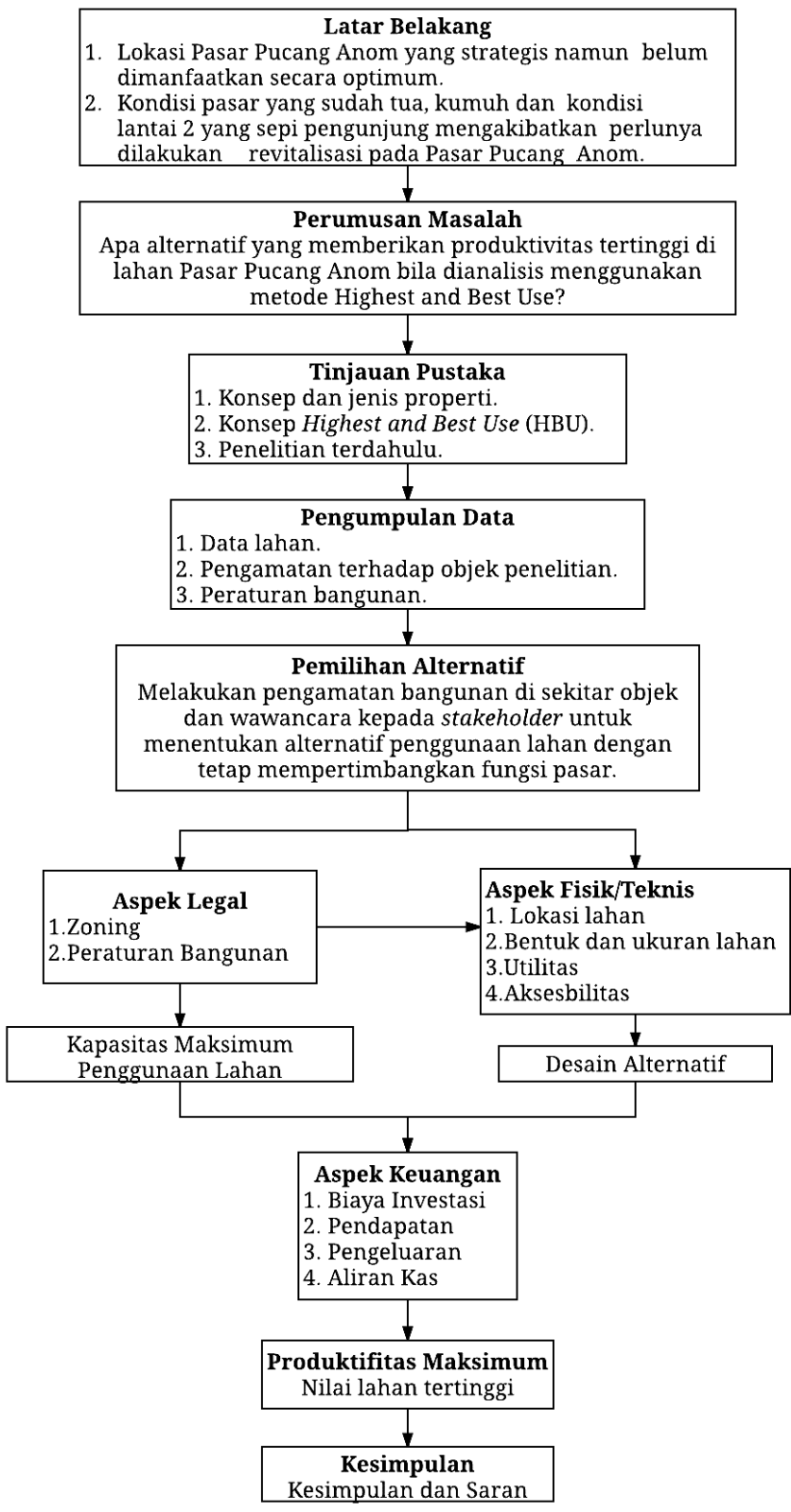

Gambar 2. Diagram Alir Penelitian

\section{Aspek Fisik}

Analisa pada aspek fisik ini terdiri dari lokasi, bentuk lahan, aksesibilitas dan ketersediaan fasilitas. Setiap alternatif dianalisis untuk mengetahui apakah memungkinkan jika dibangun berdasarkan aspek fisik yang ada.

1. Lokasi lahan

Lahan ini berada di Jalan Pucang Anom Surabaya. Lahan cocok untuk dikembangkan menjadi properti komersial karena terletak di tengah kota dan berdekatan dengan 
kawasan komersial seperti pertokoan, perkantoran, bank dan juga kawasan pemukiman.

2. Bentuk dan Ukuran Lahan

Berdasarkan data yang didapatkan, diketahui bahwa objek penelitian memiliki luas $11.615 \mathrm{~m}^{2}$ ukuran lahan berbentuk persegi panjang sehingga memudahkan untuk dikembangkan menjadi properti yang diharapkan seperti apartemen, pujasera, hotel, dan pertokoan.

3. Utilitas

Untuk menunjang aktivitas properti seperti pasar tradisional, apartemen, pujasera, pertokoan, dan hotel dibutuhkan ketersediaan air, listrik dan juga saluran telepon. Lahan memiliki kelengkapan penunjang seperti air, listrik, dan saluran telepon sehingga memungkinkan untuk dibangun alternatif properti yang diharapkan.

4. Aksesibilitas Lahan

Pada analisa ini, aksesibilitas objek akan ditinjau dari fungsi jalan dan ketersediaan transportasi umum. Diketahui lahan terletak di Jalan Pucang Anom dan merupakan jalan lokal [7]. Berdasarkan penelitian langsung ke objek penelitian, keberadaan transportasi umum seperti angkutan kota, taksi dan juga becak telah tersedia.

Hasil analisa pada aspek fisik, maka alternatif revitalisasi pasar, hotel, apartemen, pujasera, dan pertokoan memungkinkan untuk digunakan pada lahan Pasar Pucang Anom, jika ditinjau dari kriteria lokasi, ukuran dan bentuk lahan, utilitas dan aksesibilitas lahan.

\section{Aspek Finansial}

Kelayakan secara finansial dilakukan melalui analisa aliran kas, yaitu biaya investasi, pendapatan dan pengeluaran. Dikarenakan lahan Pasar Pucang Anom terdapat bangunan diatasnya dan diasumsikan sebagai lahan kosong maka perlu adanya biaya pembongkaran bangunan.

\section{Biaya Investasi}

Biaya investasi ini terdiri dari biaya pembongkaran bangunan, biaya lahan, biaya bangunan (biaya standar), dan biaya non standar. Berdasarkan metode pendekatan data pasar, nilai lahan ini didapatkan dari beberapa nilai lahan yang berada di sekitar objek penelitian, didapatkan nilai lahan sebesar Rp8.477.503,- $/ \mathrm{m}^{2}$. Hasil investasi untuk masing-masing alternatif dapat di lihat pada Tabel 2.

\section{Pendapatan}

Pendapatan ini terdiri dari biaya sewa, service charge dan pemasukan dari segi parkir. Biaya sewa didapatkan dari perbandingan data dengan properti sejenis yang ada di Surabaya. Sedangkan service charge dibebankan kepada penyewa untuk membiayai biaya operasional. Besarnya service charge berbeda sesuai dengan masing-masing alternatif.

\section{Pengeluaran}

Pengeluaran pada tiap alternatif terdiri dari biaya operasional dan biaya pemeliharaan bangunan. biaya operasional terdiri dari biaya listrik, air dan gaji pegawai. Biaya listrik dan air disesuaikan dengan tarif dasar listrik dan tarif air yang berlaku di Surabaya.

\section{Aliran Kas}

Selisih antara pendapatan dan pengeluaran tiap tahun digambarkan dalam bentuk aliran kas guna mengetahui pasar dengan penambahan properti komersial dengan luas dasar bangunan maksimal sebesar $6.969 \mathrm{~m}^{2}$ dengan jumlah lantai maksimal 5 lantai. Alternatif yang memiliki nilai pendapatan bersih tiap tahunnya. Layak tidaknya suatu alternatif dianalisis menggunakan uji kelayakan berupa NPV. Nilai NPV lebih besar dari nol maka alternatif tersebut dapat dikatakan layak.

Berdasarkan analisa pada aspek finansial didapatkan nilai NPV seperti pada Tabel 3.

Tabel 2.

Biaya Investasi Alternatif

\begin{tabular}{cc}
\hline \hline Alternatif & Biaya Investasi \\
\hline Satu & Rp295.157.225.583 \\
Dua & Rp286.500.707.583 \\
Tiga & Rp262.805.711.583 \\
Empat & Rp322.305.333.583 \\
\hline \hline
\end{tabular}

Tabel 3.

Rekapitulasi Perhitungan NPV

\begin{tabular}{cc}
\hline \hline Alternatif & NPV \\
\hline Satu & Rp18.232.427.971 \\
Dua & Rp40.054.113.063 \\
Tiga & Rp115.817.673.877 \\
Empat & $-R p 40.129 .115 .244$ \\
\hline \hline
\end{tabular}

\section{E. Produktivitas Maksimum}

Setelah perhitungan aspek finansial, tahapan selanjutnya adalah menghitung produktivitas maksimum pada masingmasing alternatif pengembangan. Berikut ini adalah produktivitas maksimum dari masing-masing alternatif pengembangan dapat di lihat pada Tabel 4.

Tabel 4.

Rekapitulasi Produktivitas Lahan

\begin{tabular}{|c|c|c|c|}
\hline No. & Uraian & Alternatif 1 & Alternatif 2 \\
\hline 1 & Nilai Properti & Rp344.367.830.115 & Rp370.534.676.558 \\
\hline 2 & Nilai Bangunan & Rp183.444.544.000 & Rp175.170.973.500 \\
\hline 3 & Nilai Lahan & Rp160.923.286.115 & Rp195.363.703.058 \\
\hline 4 & Nilai lahan/m2 & Rp13.854.781 & Rp16.819.949 \\
\hline 5 & Harga lahan awal/m2 & Rp8.477.503 & Rp8.477.503 \\
\hline 6 & Produktivitas & $63 \%$ & $98 \%$ \\
\hline No. & Uraian & Alternatif 3 & Alternatif 4 \\
\hline 1 & Nilai Properti & $\begin{array}{c}\text { Rp458.968.480.66 } \\
6\end{array}$ & $\begin{array}{c}\text { Rp222.706.146.84 } \\
5\end{array}$ \\
\hline 2 & Nilai Bangunan & $\begin{array}{c}\text { Rp153.313.560.00 } \\
0\end{array}$ & $\begin{array}{c}\text { Rp209.652.492.00 } \\
0\end{array}$ \\
\hline 3 & Nilai Lahan & $\begin{array}{c}\text { Rp305.654.920.66 } \\
6\end{array}$ & Rp13.053.654.845 \\
\hline 4 & Nilai lahan/m2 & Rp26.315.533 & Rp1.123.862 \\
\hline 5 & $\begin{array}{l}\text { Harga lahan } \\
\text { awal/m2 }\end{array}$ & Rp8.477.503 & Rp8.477.503 \\
\hline 6 & Produktivitas & $210 \%$ & $-87 \%$ \\
\hline
\end{tabular}

\section{KESIMPULAN}

Berdasarkan hasil analisa dan perhitungan, lahan pasar Pucang Anom seluas $11.615 \mathrm{~m}^{2}$ ini dapat digunakan sebagai

produktivitas tertinggi adalah alternatif 3 yaitu penggunaan mixed used antara pasar tradisional dan apartemen dengan 
nilai lahan sebesar $\mathrm{Rp} 26.315 .533 / \mathrm{m}^{2}$ dan produktivitas sebesar $210 \%$.

\section{DAFTAR PUSTAKA}

[1] B. Harjanto dan W. Hidayati, Konsep Dasar Penilaian Properti. Yogyakarta : BPFE (2014).

[2] M. Herradiyanti., C. Utomo dan Y.E. Putri, "Analisa Penggunaan Tertinggi dan Terbaik (Highest and Best Use Analysis) pada Lahan Pasar Turi Lama Surabaya,” Jurnal Teknik ITS, Vol.5, No.2 (2016) D172-D175.

[3] M. Afiata dan C. Utomo, "Alternatif Penggunaan Tertinggi dan Terbaik pada Lahan Pasar Blauran Surabaya," Jurnal Teknik ITS, Vol. 5, No.2, (2016) D128-D131.

[4] R.P.A Kasih dan C. Utomo, "Analisa Produktivitas Tertinggi dan Terbaik pada Penggunaan Lahan Pasar Genteng Baru Surabaya," Jurnal Teknik ITS, Vol. 5, No. 2 (2016) D237-D240.

[5] M.S. Mustika dan C. Utomo, "Analisa Alternatif Revitalisasi Pasar Gubeng Masjid Surabaya dengan Metode Highest and Best Use," Jurnal Teknik ITS, Vol.5, No.2, (2016). C75-C77.
[6] B. Anggarwati dan C. Utomo, "Analisa Penggunaan Lahan Kawasan Komersial Perumahan Citra Raya Surabaya dengan metode Highest and Best Use," Jurnal Teknik ITS, Vol.2, No.2 (2013) D39-D41.

[7] F.V. Faradiany dan C. Utomo, "Analisa Highest and Best Use pada Lahan Kosong di Jemur Gayung 11 Surabaya," Jurnal Teknik ITS, Vol.3, No.2 (2014) C61-C63.

[8] T.D.A. Rasyid dan C. Utomo, "Analisa Highest and Best Use (HBU) pada Lahan Bekas SPBU Biliton Surabaya,” Jurnal Teknik ITS, Vol.2, No.2 (2013) D181-D185.

[9] Kevin dan C. Utomo, "Analisa Highest and Best Use pada Lahan di Jalan Tenggilis Timur 7 Surabaya," Jurnal Teknik ITS, Vol.6, No.1 (2017) 30-34.

[10] Peraturan Daerah Kota Surabaya Nomor 12 Tahun 2014 Tentang Rencana Tata Ruang Wilayah Kota Surabaya Tahun 2014-2034.

[11] Peraturan Walikota Surabaya Nomor 57 Tahun 2015 Tentang Pedoman Teknis Pengendalian Pemanfaatan Ruang Dalam Rangka Pendirian Bangunan Di Kota Surabaya. 